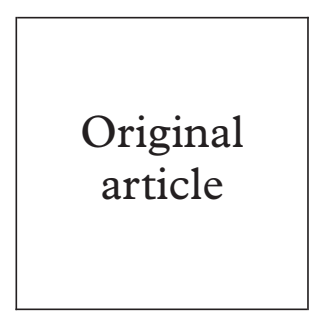

\title{
Podophyllin office therapy against condyloma should be abandoned
}

\author{
Geo von Krogh, Eric Longstaff
}

Podophyllin, a crude plant extract with low efficacy, high toxicity, and a serious mutagenicity profile does not comply with the WHO guidelines for plant derived treatments and should be removed from clinical treatment protocols. Home treatment with pharmaceutical products based on podophyllotoxin - the purified, standardised active antiwart ingredient of podophyllinrepresents safe and effective first line therapy for patients with anogenital warts. (Sex Transm Inf 2001;77:409-412)

Keywords: podophyllin; podophyllotoxin; condyloma therapy

\section{Introduction}

Patients with condylomata acuminata present to many different disciplines, and recent guidelines focus on shared management between specialists and primary care physicians. ${ }^{1-4}$ This article focuses on the advantages of purified podophyllotoxin preparations over crude podophyllin extract for safe, fast, and cost effective home treatment for condyloma eradication.

\section{Podophyllin}

The herbal extract known as podophyllin is a crude, non-standardised, and impure resin preparation obtained from the rhizomes of the Podophyllum plant species $P$ peltatum, or $P$ emodi. The antiwart ingredients are antimitotically acting lignans, ${ }^{5}$ of which podophyllotoxin is the most potent. ${ }^{\circ}$

Kaplan $^{7}$ demonstrated that topical 25\% P peltatum resin extract could accomplish regression of condylomas. However, long term efficacy rates originally claimed have not been confirmed, recurrence rates being $33-55 \%{ }^{8}$ Other drawbacks include short shelf life, risk of severe local and systemic toxicity, and mutagenic properties.

\section{QUALITY CONTROL PROBLEMS}

Extraction procedures, entailing rhizome treatment with ethanol/precipitation in acidified water, do not allow for quantitative determination of constituents, which vary between batches. Toxic ingredients often cause unpredictable and severe local toxicity including painful burns and ulcerations. Podophyllin is unstable during clinic storage, with frequent crystallisation and formation of inactive picroisomers of lignans. ${ }^{6}$

\section{HIGH TOXICITY}

Podophyllin must be applied by a trained care giver at weekly intervals. The resin must be washed off 4-6 hours after application; use of a protective inert ointment for the surrounding skin is recommended.

There is a risk of systemic intoxication, as ingredients at high concentrations may be absorbed and distributed to vital organs including the gastrointestinal mucosa, the kidneys, the bone marrow, and the CNS. Of greatest concern are the number of case reports revealing that following podophyllin painting of large condylomas, after subdermal injection into plantar warts, or following accidental ingestion, podophyllin may cause fatal or near fatal intoxication ${ }^{9-17}$ due to CNS influence, coma, respiratory depression, etc, and cardiovascular crisis. There is no known antidote. Irreversible peripheral neuropathy is a sequel in survivors. Warnings against use of volumes exceeding $0.4-0.9 \mathrm{ml}$ have been issued. ${ }^{10}$

Podophyllin contains two mutagenic flavenoids, quercetin and kaempherol, which make up $3 \%$ and $6 \%$ of the dry weight, respectively ${ }^{18-20}$ and that potentially may enhance oncogenic HPV associated intraepithelial neoplasia. ${ }^{21}$

REGULATORY ASPECTS AND SAFETY EVALUATION The WHO guidelines for evaluation of herbal remedies include tests for (1) acute toxicity; (2) long term toxicity; (3) mutagenicity and carcinogenicity; (4) reproductive toxicity; and (5) local toxicity. A formal regulatory review and safety evaluation of podophyllin has never been performed, although mutagenicity, carcinogenicity, and reproductive toxicity studies indicate that podophyllin is potentially very dangerous. $^{22-24}$

A high incidence of tumours has been reported in mice exposed to podophyllin containing wood bedding. ${ }^{22}$ Podophyllin may cause chromosomal changes in hamsters ${ }^{23}$ and may be co-carcinogenic with oestrogen therapy. ${ }^{24}$ Podophyllin induces increased mutation rates in Salmonella typhimurium, numerical chromosomal defects in mammalian cell cultures, and a high incidence of chromatid and chromosome deletions, chromatid exchanges, and cells with multiple aberrations in human lymphocytes. In mice, podophyllin seems teratogenic, inducing a high frequency of fetal mortality; in rats no teratogenic influence has been demonstrated. ${ }^{24}$ 


\section{Podophyllotoxin}

Podophyllotoxin is the active antiwart ingredient of Podophyllum; the pharmacological action is that of blocking microtubule assembly of the mitotic apparatus by binding to the tubulin..$^{59}$

LOW CLINICAL TOXICITY

In contrast with podophyllin, topical use of $0.15 \%-0.5 \%$ podophyllotoxin preparations are very safe for clinical use. In patients "drenching" extremely large condylomata plaques with excessive amounts of $0.5 \%$ podophyllotoxin solution, corresponding to $0.11 \mathrm{mg} / \mathrm{kg}$ as a single dose and $0.64 \mathrm{mg} / \mathrm{kg}$ as a cumulative dose, subsequent serum levels in the range of 1-17 $\mathrm{ng} / \mathrm{ml}$ of podophyllotoxin have been measured. Such quantities are far below levels of clinical significance ${ }^{10}$; cancer patients receiving daily intravenous injections of $0.5-10 \mathrm{mg} / \mathrm{kg}$ podophyllotoxin have not developed any injury beyond transient bone marrow depression. ${ }^{25}$ Von $\mathrm{Krogh}^{10}$ calculated that even if a $100 \%$ podophyllotoxin absorption in theory were accomplished through accidental oral intake, up to $7 \mathrm{ml}$ as a single dose would be below a level of acute toxicity. ${ }^{25}$

No washoff is required between applications $^{69}$; local side effects from topical use of podophyllotoxin are predictable and usually mild to moderate. ${ }^{6926}$ Erosions associated with successful condyloma necrosis are shallow and heal within a few days. Severe reactions such as pain requiring discontinuation of therapy are rare.

HIGH CLINICAL EFFICACY

First tested as a $0.5 \%$ ethanol solution in uncircumcised males, ${ }^{69}$ it appeared that podophyllotoxin therapy cycles (courses) for self treatment were feasible as twice daily application for 3 days, followed by 4-7 days of rest. Methyl-rosaniline added to taint the solution optimised compliance by enabling visualisation of treated warts. After a single course, $70 \%$ of preputial sac warts and $49 \%$ of all penile warts were eradicated. When another therapy course was prescribed, $82 \%$ of cases were cured at 3 months' follow up. In subsequent European key studies, ${ }^{96-30}$ cumulative long term (3-4 months' follow up) results following podophyllotoxin home therapy has consistently been more effective than podophyllin office therapy (p <0.05-0.001; table 1). The currently

Table 1 Condyloma eradication following self therapy with podophyllotoxin compared with podophyllin office therapy; complete cure rates at 3-4 months' follow up

\begin{tabular}{|c|c|c|c|c|}
\hline & \multicolumn{2}{|c|}{ Podophyllotoxin } & \multicolumn{2}{|l|}{ Podophyllin } \\
\hline & Courses & $0.5 \%$ solution twice daily 3 days & $20 \%$ once weekly & $p$ Value \\
\hline Von Krogh $1981^{9}$ & $1-2$ & $85 \%(142 / 173)$ & $38 \%(40 / 105)$ & $<0.001$ \\
\hline Lassus $1987^{27}$ & $1-4$ & $77 \%(37 / 48)$ & $44 \%(23 / 52)$ & $<0.01$ \\
\hline Edwards et al $1988^{28}$ & $1-6$ & $88 \%(28 / 32)$ & $63 \%(12 / 19)$ & $<0.05$ \\
\hline \multirow[t]{2}{*}{ Markiewicz et al $1990^{29}$} & $1-6$ & $79 \%(11 / 14)$ & $38 \%(5 / 13)$ & $<0.05$ \\
\hline & & $0.5 \%$ solution twice daily 3 days & $25 \%$ twice weekly & \\
\hline \multirow[t]{2}{*}{ Lacey et al $2001^{26}$} & $1-4$ & $63 \%(57 / 90)$ & $37 \%(33 / 90)$ & 0.001 \\
\hline & & $0.15 \%$ cream twice daily 4 days & $25 \%$ twice weekly & \\
\hline Lacey et al $2001^{26}$ & $1-4$ & $59 \%(40 / 68)$ & $37 \%(33 / 90)$ & 0.008 \\
\hline
\end{tabular}

licensed $0.5 \%$ podophyllotoxin solution containing patent blue as a colour indicator, is convenient for penile warts; the foreskin is retracted and the solution is applied to each wart using a specially designed plastic applicator or cotton wool swabs.

With the exception of a few early US based studies $^{31}{ }^{32}$ when compliance problems might have existed because of use of a colourless podophyllotoxin solution, well controlled studies on the cyclical use of 3 day courses of a $0.5 \%$ podophyllotoxin tainted solution in women have also shown good therapeutic effects against vulval warts, with clearance rates being in the range of $50 \%-77 \% .{ }^{26}{ }^{33} 34$ In recent years, the compliance aspect of podophyllotoxin treatment has been improved through the development of a white coloured $0.15 \%$ cream (Wartec, Warticon) to be rubbed into vulval and anal wart areas by the patient's index finger, following physician guided office information on their location and by self inspection through a hand held mirror. Randomised prospective studies (table 1 ) demonstrate that the $0.15 \%$ cream is generally as effective as the $0.5 \%$ tainted solution. Thus, Lacey et al ${ }^{26}$ showed that all original warts disappeared in $78 \%$ of patients given the cream versus in $58 \%$ of podophyllin treated patients $(p<0.01)$ and that the long term cure rate was highly superior in the favour of the cream versus that of $25 \%$ podophyllin ( $59 \%$ versus $46 \%$; $<<0.001)$. Cost calculations show that although podophyllin is cheap to produce, it is less cost effective when compared with podophyllotoxin home therapy. ${ }^{26}$

\section{REGULATORY ASPECTS AND EXPERIMENTAL} SAFETY EVALUATIONS

The licensed $0.15-0.5 \%$ podophyllotoxin products have been assessed in terms of chemistry, pharmacology, and toxicology. The experimental toxicology data, published in further detail elsewhere, ${ }^{24}$ are briefly compiled in the current survey.

\section{Toxicity studies}

Oral bioavailability in dogs following high doses $(1.0 \mathrm{mg} / \mathrm{kg})$ is up to $63 \%$ compared with intravenous administration, peak plasma levels occurring at 1-8 hours followed by a sharp decline and with only trace amounts detectable at 24 hours. Only doses of $1.0 \mathrm{mg} / \mathrm{kg}$ cause detectable CNS levels at 2-8 hours. In mice, both kidney and biliary excretion occurs; after 24 hours all organs and body fluids with the exception of the liver, the intestines, and urine are cleared. In pregnant mice, podophyllotoxin may reach higher concentrations in fetal than in maternal organs such as the bone marrow, spleen, thymus, lymph glands, and the dental pulp/dentine edge.

\section{Carcinogenicity and genotoxicity}

Rats and mice receiving up to $0.3 \mathrm{mg} / \mathrm{kg} /$ day of podophyllotoxin in the diet for 104 and 80 weeks, respectively, have not shown any evidences of an oncogenic effect. In Salmonella typhimurium podophyllin induced up to 13.6fold increase in revertant numbers, while 
Table 2 20\% Podophyllin versus $0.15-0.5 \%$ podophyllotoxin

\begin{tabular}{ll}
\hline Podophyllin & Podophyllotoxin \\
\hline Non-standardised, unstable & Standardised, stable \\
Local toxicity high & Local toxicity low \\
Systemic toxicity high & Systemic toxicity negligible \\
Teratogenic and fetotoxic & Non-teratogenic \\
High mutagenicity & No mutagenicity \\
Carcinogen effect? & No carcinogen effect \\
Low efficacy & High efficacy \\
Clinic treatment & Self treatment \\
High treatment cost & Moderate treatment cost \\
\hline
\end{tabular}

podophyllotoxin exposure merely resulted in a 1.5-1.6-fold increase attributed to chance with no dose relation.

PHA stimulated human lymphocyte cultures exposed to podophyllotoxin for 25 hours did not show any clastogenic effect. No mutagenic potential has been detected in ovarian and lymphoma cell cultures, and no single strand DNA breakage has been detected in human cell cultures.

\section{Local sensitisation potential}

In the guinea pig maximisation test $0.1 \%$ and $0.5 \%$ podophyllotoxin preparations caused toxic reactions associated with the cutaneous necrosis but did not show any immunological sensitising properties. ${ }^{35}$

\section{Reproductive toxicity}

Podophyllotoxin is not teratogenic to rats or rabbits. Pregnant rats and their offspring were followed after oral administration of $0.4,1.0$, or $2.5 \mathrm{mg} / \mathrm{kg} /$ day podophyllotoxin from the 15 th day of gestation to the 21 st day post partum. There were no influences on fertility, gestation, mating, litter size, embryonic or fetal development, or perinatal and postnatal behaviour. A negative influence was observed in the offspring exposed to the highest dose $(2.5 \mathrm{mg} / \mathrm{kg})$ regarding survival rate, as well as delayed development and weight gain of survivors. There was no influence in exposed animals on the rate of malformations, birth weight, behaviour, or on fertility or mating in podophyllotoxin exposed mothers or in their first/second generation offspring.

Although reproductive toxicity studies in animals have not shown teratogenicity and the half life appears to be short and systemic elimination occurs within a few days, we still believe that podophyllotoxin should be avoided during pregnancy since the possibility cannot be excluded that the drug might accumulate in the human fetus. As a further precaution, we also recommend that conception should be avoided during the week following completion of podophyllotoxin therapy.

\section{Conclusions}

Use of the crude herbal remedy podophyllin is associated with low production costs, but the cost benefit versus the risk ratio of the product is highly questionable. Further podophyllin use is not only redundant but should be abandoned in favour of its modern pharmaceutical replacement-that is, podophyllotoxin preparations with well defined pharmacokinetic, metabolic, and toxicity safety profiles. Podophyllotoxin solution and cream have been documented as safe and effective for self therapy of anogenital warts (table 2) and are recommended as first line therapy.

1 UK National guidelines for the management of anogenital warts. Clinical Effectiveness Group (Association of Genitourinary Medicine and the Medical Society for the Study of Venereal Diseases). Sex Transm Infect 1999;75(Suppl 1):71-5.

2 Von Krogh G, Lacey CJN, Gross G, et al. European Course of HPV-associated pathology: guidelines for primary care physicians for the diagnosis and management of anogenital warts. Sex Transm Inf 2000;76:162-8.

3 CDC 1998 guidelines for treatment of sexually transmitted diseases. Centers for Disease Control and Prevention. Morb Mortal Weekly Report 1998;47(RR-1):1-111.

4 Ferenczy A, von Krogh G. External genital warts: current and new therapies. In: Monsenego J, ed. Management of anogenital condylomata acuminata: an update. Paris, France: EUROGIN Scientific Publications, 2000:21-27.

5 Kelly MG, Hartwell JL. The biological effects and the chemical composition of podophyllin. A review. F Natl Can Inst 1954;14:967-80

6 Von Krogh G. Podophyllotoxin for condylomata acuminata eradication. Clinical and experimental comparative studies on Podophyllum lignans, colchicine and 5-fluorouracil. Thesis. Acta Dermatovenereol 1991;Suppl 98:1-48.

7 Kaplan IW. Condylomata acuminata. New Orleans Med Surg f 1942;14:936-45.

8 Strauss MJ, Khanna V, Koenig JD, et al. The cost of treating genital warts. Int f Dermatol 1996;35:340-8.

9 Von Krogh G. Penile condylomata acuminata: an experimental model for evaluation of topical treatment with $0.5 \%-1.0 \%$ ethanolic preparations of podophyllotoxin for three days. Sex Transm Dis 1981;8:179-84.

10 Von Krogh G. Podophyllotoxin in serum: absorption subsequent to three-day repeated application of a $0.5 \%$ ethanol preparation on condylomata acuminata. Sex Transm Dis 1982;9:26-30.

11 Filley CM, Graff-Radford NR, Lacy R, et al. Neurological manifestations of podophyllin toxicity. Neurology 1980;32: 308-11.

12 Cassidy DE, Drewry J, Fanning JP. Podophyllum toxicity: a review of a fatal case and a review of the literature. $\mathcal{F}$. Toxicol-Clin Toxicol 1982;19:35-44.

13 West WM, Ridgeway NA, Morris AJ, et al. Fatal podophyllin ingestion. South Med f 1982;75:1269-70

14 Dobb GJ, Edis RH. Coma and neuropathy after ingestion of herbal laxative containing podophyllin. Med $\mathcal{F}$ Aust 1984;140:495-6.

15 Heath A, Mellstrand T, Ahlmen J. Treatment of podophyllin poisoning with resin hemoperfusion. Human Toxicol 1982; 1:373-8.

16 Lund O, Marstrander J, Smedby B, et al. Podophyllin. Systemic intoxication following intracutaneous injection of plantar warts. F Norw Med Assoc 1988;108: 1293.

17 Tomczak RL, Hake DH. Near fatal systemic toxicity from local injection of podophyllin for pedel verrucae treatment. f Foot Surg 1992;31:36-42.

18 Bjeldanes LF, Chang GW. Mutagenic activity of quercetin and related compounds. Science 1977;197:577-8.

19 Pamucku AM, Yalciner S, Hatcher JF, et al. Quercetin, a rat intestinal and bladder carcinogen present in bracken fern intestinal and bladder carcinogen present in bracken
(Pteridium aquilinum) Cancer Res 1980;40:3468-72.

20 Petersen CS, Weisman K. Quercetin and kaempherol: an argument against the use of podophyllin? Genitourin Med 1995;71:92-3

21 Von Krogh G, Horenblas S. The management and prevention of premalignant penile lesions. Scand f Urol Nephrol 2000; (Suppl) 205:220-9.

22 Sabine JR, Horton BJ, Wicks MB. Spontaneous tumours inC3H-Avy and C3H-Avy FB mice: high incidence in the United States, low incidence in Australia. 7 Natl Cancer Inst 1973;50:1237-42.

23 Ferguson LR, Pearson A. Chromosomal changes in Chinese hamster AA8 cells caused by podophyllin, a common treatment for genital warts. Mut Res 1992;266:231-9.

24 Longstaff E, von Krogh G. Condyloma eradication: Longstaff E, von Krogh G. Condyloma eradication:
self-therapy with $0.15 \%-0.5 \%$ podophyllotoxin versus $20-25 \%$ podophyllin - an integrated safety assessment. 7 Regul Toxicol Pharmacol 2001;33:117-37.

25 Savel H. The metaphase-arresting plant alkaloids and cancer chemotherapy. Prog Exp Tumor Res 1966;8:189-224.

26 Lacey C, Maw R, Kinghorn GR, et al. Randomised controlled and economic evaluation of patient-applied podophyllotoxin solution or cream or clinic-applied podophyllin in the treatment of genital warts. Sex Transm Inf 2001; (accepted).

27 Lassus A. Comparison of podophyllotoxin and podophyllin in treatment of genital warts. Lancet 1987;2:512-13.

28 Edwards A, Atma-Ram A, Thin RN. Podophyllotoxin 0.5\% versus podophyllin $20 \%$ to treat penile warts. Genitourin Med 1988;64:263-5.

29 Marzukiewicz W, Jablonska S. Clinical efficacy of condyline ( $0.5 \%$ podophyllotoxin) solution and cream vs podophyllin in the treatment of external condylomata acuminata. $\mathcal{F}$ Derin the treatment of external condy

30 Kinghorn GR, McMillan A, Mulcahy F, et al. An open comparative study of the efficacy of $0.5 \%$ podophyllotoxin 
lotion and $25 \%$ podophyllin solution in the treatment of condylomata acuminata in males and females. Int 7 STD condylomata acumin

31 Greenberg MD, Rutlidge LH, Reid R, et al. A double blind randomised trial of $0.5 \%$ podophilox and placebo for the treatment of genital warts in women. Obstet Gynecol 1991; 77:735-9.

32 Kirby P, Dunne A, King DH, et al. Double-blind randomized clinical trial of self-administered podofilox solution versus vehicle in the treatment of genital warts. $A m$ f Med 1990;8:465-9.
33 Strand A, Brinkeborn R-M, Siboulet A. Topical treatment of genital warts in men, an open study of podophyllotoxin cream compared with solution. Genitourin Med 1995;71: 387-90.

34 Claesson U, Lassus A, Happonen $\mathrm{H}$, et al. Topical treatment of venereal warts: a comparative open study of podophyllotoxin cream versus solution. Int F STD AIDS 1996;7:42934.

35 Von Krogh G, Maibach HI. Guinea pig maximisation test. Podophyllum lignans. Contact Dermatitis 1983;9:95-8.

\title{
7th European Forum on Quality Improvement in Health Care
}

\author{
21-23 March 2002 \\ Edinburgh, Scotland
}

We are delighted to announce this forthcoming conference in Edinburgh. Delegate enquiries are welcome.

The themes of the Forum are:

- Leadership, culture change, and change management

- Achieving radical improvement by redesigning care

- Health policy for lasting improvement in health care systems

- Patient safety

- Measurement for improvement, learning, and accountability

- Partnership with patients

- Professional quality: the foundation for improvement

- Continuous improvement in education and training

- People and improvement.

Presented to you by the BMJ Publishing Group (London, UK) and Institute for Healthcare Improvement (Boston, USA). For more information contact: quality@bma.org.uk or look at the website www.quality.bmjpg.com. Tel: +44 (0)20 7383 6409; fax: +44 (0)20 73736869. 